\author{
To appear in Everything Flows: Towards a Processual Philosophy of Biology \\ Edited by Daniel J. Nicholson and John Dupré \\ Oxford University Press (2018)
}

\begin{abstract}
A crucial question for anyone willing to defend a process view of the biological world is how to identify a process and how to follow it through time. Here I suggest that the "genidentity" view (suggested first by psychologist Kurt Lewin, and then further explored by philosopher Hans Reichenbach, mainly in the context of physics) can contribute decisively to this project. According to the genidentity view, the identity through time of an entity $\mathrm{X}$ is nothing more than the continuous connection of the states through which X goes. In this paper, I explain how the genidentity view addresses the long debated problem of what constitutes diachronic identity in the biological world. I describe the centrality of the concept of genidentity in David Hull's reflection on biological identity, and I then suggest an extension of Hull's view on the basis of recent data demonstrating the ubiquity of symbiotic interactions in the living world. Finally, using immunological interactions as a key example, I show that the genidentity view sheds light on process biology by suggesting that the main interest of a process approach is epistemological rather than ontological, and that the main claim of a process approach is one of priority, that is, the claim that processes precede and define things, and not vice versa.
\end{abstract}

Key words

Continuity; Genidentity; David Hull; Identity; Immune system; Individuality; Process; Symbiosis.

\title{
0. Introduction
}

What exactly is a process view of life? Philosophers of biology and biologists who have recently defended such a view ((Dupré, 2012); (Bapteste \& Dupré, 2013); (Dupré, 2014)) generally oppose processes (characterized by constant change) and things (characterized by stability and durability). But two major questions should be raised regarding this view:

(i) What kinds of relationships between 'things' and 'processes' are possible? Is it possible to countenance both 'things' and 'processes' as categories to describe the living world, or are these two categories incompatible?

(ii) Can a priority claim about 'things' and 'processes' be made and, if so, on which ground? Here the question is to determine what comes first - things or processes. Two main types of priority claims can be made: an ontological one (the biological world is actually made of processes, and things are only partial and temporary stabilizations of processes), or an epistemological perspective (the best way to understand the biological world for us, as human beings, is to get access to it in terms of processes). (On processes in general, and on the opposition between processes and substances, see (Seibt, 2013), as well as Seibt, this volume). 
In this chapter, I would like to show that a preexisting view of the biological world, called the "genidentity view," especially in the variant defended by David Hull, helps clarify what a process view of life might be. More specifically, the genidentity view is useful because it suggests that: a) both the notions of processes and things are needed in biology, but processes are prior to things; b) the main interest of adopting a process view is epistemological, not ontological. One key underlying objective of the present chapter will be to address a question that seems decisive for anyone who proposes to conceive of the biological world in terms of processes, namely "What difference does it make, in actual practice, to adopt a process view?"

Let us start with a preliminary definition of the notion of "genidentity." In a nutshell, the genidentity view, which has been explored in the contexts of psychology, physics, and biology ((Lewin, 1922), (Reichenbach, 1956), (Hull, 1992); (Boniolo \& Carrara, 2004); (Pradeu \& Carosella, 2006b); (Guay \& Pradeu, 2016b)), says that the identity through time of an entity $\mathrm{X}$ is given by a well-identified series of continuous states of affairs. Of course, this claim is not sufficient in itself; every precise application of the genidentity view requires a clarification of exactly which continuous states are being followed, and why. In what follows, I examine in detail the concept of genidentity, and then I show why it could constitute a decisive building block for the project of developing a process view for biology. After a short reminder about the origins of the concept of genidentity, I describe its centrality in David Hull's reflection on biological identity, and I then suggest an extension of Hull's view on the basis of recent data demonstrating the ubiquity of symbiotic interactions in the living world. Finally, I explain why genidentity leads us to adopt a multilevel and mainly epistemological view on biological processes.

\section{What is genidentity, and how can this concept be applied to the living world?}

What constitutes the identity through time of an entity X? For instance, in what sense can I be said to be the "same" as the child I was, a cat the "same" as the kitten it was, or a wave the "same" wave while it is moving through the sea? Those questions are particular instances of the more general problem of diachronic identity (or identity through time), undoubtedly one of the most fundamental and most debated problems of all philosophy. That problem has been raised by major philosophers of the past, including Aristotle, Locke, and Leibniz, among many others. More recently, metaphysicians (both "perdurantists" and "endurantists") have offered important analyses of the same problem, e.g., David Wiggins (2001), Peter van Inwagen (1990), Theodore Sider (2001), and Katherine Hawley (2004).

One very interesting, though often neglected, way to address the problem of diachronic identity is to resort to the concept of "genidentity," suggested by psychologist Kurt Lewin, and then further explored by philosopher of science Hans Reichenbach. What is genidentity? According to the genidentity view, the identity through time of an entity $\mathrm{X}$ is given by a well-identified series of continuous states of affairs. As will become clear in what follows, this view insists on continuity of states rather than prior existence of objects, it conflicts radically with several forms of substantialism, and it is based on an epistemological (rather than ontological) attitude regarding science.

The concept of "genidentity" was proposed in 1922 by Kurt Lewin (1890-1947), a leading German-American psychologist, as a way to better understand identity through time (Lewin, 1922). The concept of genidentity has been neglected by most philosophers of science, but it was taken very seriously by Hans Reichenbach (1891-1953). Indeed, Reichenbach examined different conceptions of genidentity, and applied them to several physical cases (Reichenbach, 1956) (on the different versions of the genidentity concept for 
Reichenbach, see (Padovani, 2013) and (Guay \& Pradeu, 2016b)). Today, however, the notion of genidentity is rarely used in philosophy in general, and almost never used in philosophy of science (with some rare exceptions, e.g., (Hull, 1992); (Boniolo \& Carrara, 2004); (Pradeu \& Carosella, 2006b); (Guay \& Pradeu, 2016b)).

By insisting on defining identity as a mere continuity, the concept of genidentity echoes in part John Locke's conception of identity. Indeed, in the second edition of his Essay, Locke (Locke, 1975 [1694]) says that the long-sought "principle of individuation" is to be found in a simple continuity of states. In the case of living things (plants or animals), the identity of a being is, according to Locke, the continuity of one and the same "life." This illustrates what has been said above, namely that genidentity views always need to make clear exactly which states are followed, and why (here, the continuity of a "life"). Applied to humans, Locke's view is the following:

This also shows wherein the Identity of the same Man consists; viz. in nothing but a participation of the same continued Life, by constantly fleeting Particles of Matter, in succession vitally united to the same organized Body. (Locke 1975 [1694], §6, 331).

Interestingly, in his New Essays, which constitute a systematic response to Locke's Essay, Leibniz (Leibniz, 1916 [1765]) strongly rejects Locke's conception of identity because, for Leibniz, continuity by itself is insufficient to define identity:

By itself continuity no more constitutes substance than does multitude or number . . Something is necessary to be numbered, repeated and continued (Leibniz 1916 [1765], 169).

Let us call substantialism the view according to which the identity of a thing X must be understood as the identity of a substance identified beforehand, and continuism the view according to which the identity of a thing $X$ is given by a mere continuity of states (as defended by Locke). Substantialism is defended by Leibniz, but also by many contemporary philosophers, under different forms. One version of substantialism is essentialism, which states that what makes the identity of $\mathrm{X}$ through time is that a core constituent or characteristic of $\mathrm{X}$ remains constant through time. For example, genetic essentialism says, in the case of living things, that a living thing remains the same through time in virtue of the fact that it possesses the same genome throughout (Kripke, 1980). Another, significantly different, version of substantialism is the "Neo-Aristotelian" view defended by David Wiggins (Wiggins, 2001). According to this view, the identity of a thing $\mathrm{X}$ is given by a sortal concept (a category), which defines a specific principle of activity (for example, it is possible to understand the identity of a given thing only by determining that it is, say, a dog, and that what defines the identity of a dog is a certain principle of activity, common to all dogs).

I suggest here that the genidentity view constitutes a particularly interesting and fruitful version of continuism (and, therefore, a view that stands in contrast with substantialism in general), and that it can shed light on the question of the diachronic identity of living things. More precisely, I would like to defend the view that genidentity is the best way to understand the diachronic identity of a living thing, and that it helps make the concept of biological process more precise. I first explain the centrality of the notion of genidentity in Hull's thinking about the problem of individuality, and then how his view can be extended to reflect important findings in recent biology, in particular regarding the phenomenon of symbiosis.

\section{The inconspicuous centrality of genidentity in David Hull's conception of biological individuality}


David Hull (1935-2010) was undoubtedly one of the most influential philosophers of biology. Hull mentioned the notion of genidentity several times in his writings ((Hull, 1986); (Hull, 1992)), but these mentions remained largely unnoticed, and, intriguingly, other philosophers of biology did not follow Hull and did not adopt this notion.

How does Hull apply the idea of genidentity more specifically? In other words, which states should one follow to understand the identity of a living thing? Hull's answer is that one should follow the continuity of an internal organization. Let us try to explain this idea in more detail.

Even before Hull used the notion of genidentity explicitly, the idea behind that notion was already present in his writings. In particular, the idea of genidentity underlies his view of identity presented in one of his most famous and influential texts, "A Matter of Individuality" (Hull, 1978). This paper by Hull is often seen as a defense of two theses, namely that species are individuals rather than classes, and that there is no "human nature," no "essence" of humanity (indeed, if humans are considered from the species point of view, that is, as Homo sapiens, it is impossible to define what are the necessary and sufficient characteristics that would make a given entity a human). Nevertheless, what in fact constitutes the basis of these two theses is the conception of identity defended by Hull, a conception that is also at the heart of what is arguably the most important contribution of that paper, that is, the two diagrams drawn by Hull. Let us now see what exactly is the conception of identity held by Hull, and why it can be important for our argumentation.

The starting point of Hull is that, at least since Aristotle, most philosophers have had a naïve view of biological individuality. Indeed, philosophers often use fictitious examples and, when they speak of a living thing, they generally mean in fact an animal, and even, in most cases, a higher vertebrate (a horse, a cat, etc.). In contrast, Hull insists on the importance of examples that are both more realistic and more diverse. According to Hull, these examples are more fascinating, more complex, and in the end more challenging, than the fictitious examples and thought experiments favored by metaphysicians (the same idea is developed in (Hull, 2001)). Taking into account the actual diversity of the living world also implies, for Hull, a suspicion towards conceptions of biological individuality based on common sense and intuitive perception. Indeed, commonsense individuation is too strongly biased by our relative size and perception abilities ((Hull, 1978); (Hull, 1992)). For example, when dealing with many plants, colonial animals, fungi, microbes, etc., common sense individuation is helpless. Some cases have been much discussed in the biological and the philosophical literature, for example dandelions, aspens, social insects, ascidians, siphonophores, biofilms, etc. (on these examples, see for instance (Pradeu, 2012); (Bouchard \& Huneman, 2013); (Guay \& Pradeu, 2016a)).

In contrast to common sense and intuitive perception, Hull seeks to offer a biologically precise criterion for the diachronic identity of biological individuals, and he finds this criterion in the idea of continuity of change. According to Hull, organisms and species belong to the same ontological category, as both must be understood as spatiotemporally localized entities. More radically, Hull's thesis is that any organism/any species is a portion of space and time. Every organism has a starting point and an end, and goes through different but continuous states between these two extremes. Exactly the same is true of every species. For Hull, because living things can undergo massive and unpredictable change, retention of substance (the idea that something of $\mathrm{X}$ remains through time) and resemblance (the idea that $X$ looks sufficiently like itself) are useless criteria for biological diachronic identity, and the only satisfying criterion is continuity of change. 
To describe and defend this continuity-based conception of identity, Hull explicitly endorses the notion of "genidentity" in several texts, and he grounds it in the idea of a continuous internal organization:

Three traditional criteria for individuality in material bodies are retention of substance, retention of structure, and continuous existence through time (genidentity). If organisms are to count as individuals, then the first two criteria are much too restrictive. In point of fact, many organisms totally exchange their substance several times over while they retain their individuality. Others undergo massive metamorphosis as well, changing their structure markedly. If organisms are paradigm individuals, then retention of neither substance nor structure is either necessary or sufficient for continued identity in material bodies. The idea that comes closest to capturing individuality in organisms and possibly individuals as such is genidentity. As its name implies, this criterion allows for change just as long as it is sufficiently continuous. The overall organization of any entity can change but it cannot be disrupted too abruptly. (Hull, 1992).

But this is already the very same conception of identity that underlies Hull's (1978) fundamental diagrams (see Figures 1 and 2). These two figures offer a description of structural patterns of change in the living world, equally applicable to organisms and species.

[Insert Figure 1 about here]

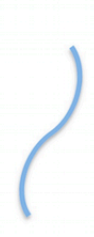

$1 \mathrm{a}$

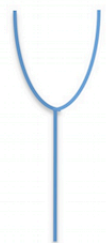

$1 \mathrm{~b}$

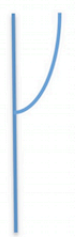

$1 \mathrm{C}$

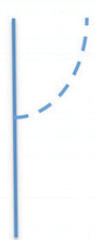

$1 d$

Figure 1. Ontogenetic change and splitting giving rise to the production of new organisms (in the case of organisms), or phylogenetic change and splitting leading to speciation (in the case of species) Based on Hull 1978.

Figure 1 illustrates structural changes associated either with change of a living entity, or with its splitting into two living entities. For Hull, a new entity emerges from a given entity if and only if the internal organization of the original entity is strongly disrupted ${ }^{1}$. This criterion of disruption of internal organization is not always easy to apply, and by definition the observer often faces a continuum of possible situations, but the examples given by Hull are very helpful. A living entity remains the same (case 1a) even if it undergoes a limited change, or even a radical change, provided that the continuity between these different states can be established (e.g., a caterpillar becoming a butterfly). In contrast, the phenomenon of splitting (case 1b) is characterized by a disruption of internal organization: one individual becomes two individuals, and the initial individual disappears as such. Transverse fission in paramecia is an example. In other situations, an individual appears on another, preexisting, individual, with the new individual becoming progressively autonomous (case 1c). An example is strobilization in certain forms of Scyphozoa (sometimes colloquially called "true jellyfish"). In still other cases, a small part of an individual (contrary to case $1 \mathrm{c}$, this is a part of an individual, not a growing individual on an individual) gains independence and becomes itself

\footnotetext{
1 "The relevant consideration is how much of the parent organism is lost and its internal organization disrupted" (Hull, 1978, p. 345)
} 
a new individual (case 1d). An example is budding in Hydrozoa (Hydrozoa are Cnidaria that, at least for most of them, have both a polypoid and medusoid stage in their lifecycles). Though classifying all the diversity of real biological phenomena of change and splitting into these four cases would probably prove very difficult, what seems clear and useful is the criterion used by Hull, who asks systematically whether the overall organization of the entity under consideration is disrupted or not. (Importantly, there is transgenerational material continuity between a parents and its offspring, but they are characterized by two different internal organizations, and it is precisely this criterion that makes the difference between the continuity of one being and the continuity of several beings through reproduction).

[Insert Figure 2 about here]

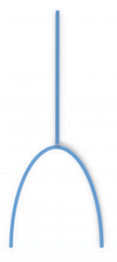

$2 \mathrm{a}$

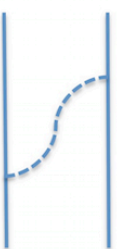

$2 \mathrm{~b}$

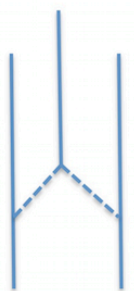

$2 \mathrm{C}$

Figure 2. Total or partial merging between organisms, or between species. Based on Hull 1978.

Figure 2 describes the merging of two living entities, or of their parts. To distinguish among the different possible situations, it is here again the criterion of disruption of internal organization that is used by Hull. Two entities can fuse to become one single entity, and remain one entity for a significant period of time, so the two initial individuals are lost (case 2a) (fusion in amoebas do not constitute an adequate illustration of this case, while the fusion of two germ cells does). In other situations (case $2 \mathrm{~b}$ ), a portion of a first individual becomes a portion of a second individual, the two individuals continue their existence, but both have changed (the first has lost a part, the second has gained a part). Blood transfusion or bacterial conjugation are good examples. In still other situations, a portion of a first individual and a portion of a second individual merge to form a third (new) individual, while the two initial individuals continue their existence (case 2c). Sexual reproduction is a good example. Applied to species rather than organisms, a good example of $2 \mathrm{~b}$ is introgression, and a good example of $2 \mathrm{c}$ is speciation by polyploidy (a rather common event in plants, for instance).

In conclusion, Hull endorsed the genidentity view. For him, what biologists can and must do to account for the continuously changing identity of any living thing is to follow its changes through time, keeping in mind that it remains the same only as long as its internal organization remains the same or changes progressively.

Naturally, one immediate difficulty faced by Hull's account of biological identity is to offer a precise definition of what "internal organization" (and its disruption) means. Suggestions to move towards that direction will be made in section 4, but, for now, I would like to show why recent biological data about symbiosis strengthen Hull's line of argument.

\section{Why the case of symbiosis strengthens the genidentity view}


As we have seen, Hull claims that, because living entities can change, merge, and split, it is crucial, in order to understand their diachronic individuality, to be able to actually follow them through time. But how frequent are events of merging and splitting in the living world? Though Hull mentions several important examples of fusion and splitting, symbiosis does not play an important role in his demonstration (apart from the rapid mention of the endosymbiotic event that is at the origin of some organelles). Now, research done on symbiosis in the last two decades or so shows that symbiotic events of fusion and splitting are much more frequent than had traditionally been assumed ((McFall-Ngai, 2002); (McFall-Ngai et al., 2013); (Gilbert \& Epel, 2015)). In fact, we will see that the pervasiveness of symbiosis proves that Hull's diagrams, which at first sight might seem to concern only a limited number of biological cases, describe situations that are in fact very frequent in nature. Indeed, by taking into account symbioses, one realizes that living things are massively like $2 \mathrm{a}$ (fusion) or $2 \mathrm{~b}$ (integration with continuation) or, even more frequently, "inverted 1c" (internalization) (see Figure 3), and that they can also split more often than is usually thought.

[Insert Figure 3 about here]

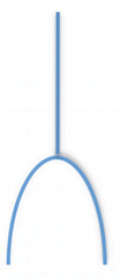

$3 \mathrm{a}$

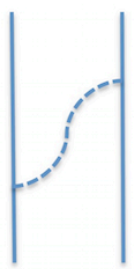

$3 \mathrm{~b}$

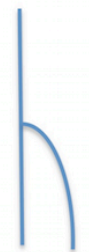

$3 \mathrm{C}$

Figure 3. Forms of integration of external biological material, at the organism level or the species level. The first case corresponds to Hull's 2a (fusion), the second to Hull's $2 b$ (integration with continuation), while the third case is an inversion of Hull's 1c. The third case (absent in Hull's analysis) can be called "internalization," and is described in this chapter as an extremely frequent (though long overlooked) phenomenon in nature.

"Symbiosis" can be understood here in the very broad sense of any close and lasting interaction between two biological entities belonging to two different species. This is in accordance with the traditional definition of Anton de Bary, formulated in 1879 (see, e.g., Sapp, 1994). Adopting this extensive definition is important here, as it can cover cases that range from mutualism (in which the fitness of the two partners is increased by the interaction), to commensalism (a neutral interaction), and to parasitism (in which the fitness of one partner increases, while the fitness of the other decreases). Indeed, all these different cases exist among the recently documented examples of symbioses.

Important events of symbiotic fusions occur both at the level of organisms and at the level of species. At the level of organisms, symbioses, long thought to be rather rare, are now considered almost ubiquitous ((McFall-Ngai et al., 2013); (Gilbert \& Epel, 2015)). Indeed, probably all organisms are hosts of many microorganisms, very often in close and longlasting associations. Very well documented cases include plants, hydra, cnidarians, sponges, fishes, the squid Euprymna scolopes, insects, mice, and humans ((Bosch \& McFall-Ngai, 2011); (Nyholm \& McFall-Ngai, 2014)). There is often a co-construction of the host and the microbes, as illustrated by cases such as legume-Rhizobia (Oldroyd, 2013) or E. scolopesVibrio (Nyholm \& McFall-Ngai, 2004) interactions. In many cases, the association is beneficial to one of the partners, or to both. In particular, and perhaps counter-intuitively, it is frequently the case that interactions with some microbes shape and strengthen the host 
immune system ((Pradeu \& Carosella, 2006b); (Round \& Mazmanian, 2009)). Very interesting cases include those where some microbes are indispensable for the development of the host ((McFall-Ngai, 2002); (Pradeu, 2011)). The notion of heterogeneous organism ((Pradeu, 2010); (Pradeu, 2012)) captures this very broad idea that all known organisms seem to harbor huge quantities of biological entities belonging to other species, and that, in many of them, those biological entities become so integrated into the host that they can be considered as parts of it. Which of these cases will count as merging events, as described by Hull? The decision for each case will depend, here again, on the degree of disruption of internal organization. For example, the legume-Rhizobia symbiosis offers a clear case of merging, and, more precisely, of internalization (case 3c, which can also be called "inverted 1c"). The plant could live without the bacteria, but the recruitment of the bacteria at the root level helps the plant decisively (the rhizobia create ammonia from nitrogen in the air, which is used by the plant to create amino acids and nucleotides), and the bacteria are very significantly transformed during the process, differentiating into bacteroids. The association between the two partners eventually constitutes a unit that displays a high degree of internal organization. In contrast, the colonization of a host by a microbe (be it pathogenic, commensal, or mutualistic) which would not remain for long in the host, which would not be transformed by this interaction, and which in turn would not have a deep effect on the overall organization of the host, would not count as a case of merging.

Symbiotic events of merging also happen at the species level. A nice example is the Aphid-Buchnera (more precisely Acyrthosphion pisum-Buchnera aphidicola) obligate symbiotic association. Approximately 160-280 million years ago (Shigenobu \& Wilson, 2011), an aphid ancestor was infected with a free-living eubacterium, and this eubacterium became established within aphid cells. The host and the Buchnera endosymbiont became interdependent and unable to survive without each other. The growth of Buchnera became integrated with that of the aphids, which acquired the endosymbionts from their mothers before birth. Speciation of host lineages was paralleled by divergence of associated endosymbiont lineages, resulting in parallel evolution of Buchnera and aphids (Baumann et al., 1995). Today, the aphid-Buchnera association (almost all of 4,000 extant species of aphid harbor an obligate Buchnera symbiont) constitutes one of the best-documented cases of an obligate symbiosis, where none of the partners can survive and reproduce without the other (Shigenobu \& Wilson, 2011). In such situations, the physiological and reproductive integration between the host and the bacteria is so tight that it makes sense to talk about a single unit, constituted by this association.

Merging events can also happen between a virus and a host species (Pradeu, 2016). For example, many parasitoid wasps have integrated a polydnavirus into their genome several million years ago; such polydnaviruses have a beneficial effect on the parasitoid wasps: they enable them to realize their life cycle by laying their eggs into their hosts, where then their offspring grow, often killing the host progressively. In fact, the wasp eggs can survive and develop only because a virus integrated into the wasp's genome actively counters the immune defense of the host larva ((Edson, Vinson, Stoltz, \& Summers, 1981); (Espagne et al., 2004); (Bézier et al., 2009)). Many specialists consider that the virus has been so tightly integrated into the host genome that it is no longer possible to see the virus and the wasp as separate entities (Roossinck, 2015); on host-virus mutualisms, see also (Virgin, Wherry, \& Ahmed, 2009)).

In many cases, therefore, symbiosis can give rise to new lineages, constituted by the merging of two individuals belonging to different species, and which subsequently reproduce as new reproductive units. The idea that symbiotic events are crucial in evolution and can even lead to the appearance of new species ("symbiogenesis") is not new ((Wallin, 1927); (Margulis \& Fester, 1991); (Margulis \& Sagan, 2002)), but this phenomenon has recently 
been illustrated by several examples, including some of those mentioned above. It seems legitimate, in these cases, to use the notions of heterogeneous species and heterogeneous lineages, on the model of the above mentioned heterogeneous organism (on this issue, see also (Dupré \& O'Malley, 2009) and (Bouchard, 2010); more generally, on the integration of "foreign" genetic material, in particular through horizontal gene transfer, see (Doolittle \& Bapteste, 2007) and (Bapteste et al., 2012)).

What about, now, cases of symbiotic splitting? In fact, taking into account symbioses is likely to lead to a very dynamic view of biological individuality, because many symbiotic interactions change through time. For example, humans are hosts to billions of microbes from birth to old age, but the composition of their microbiome changes significantly through time. Immediately at birth, bacteria colonize the baby, upon passage through the birth canal. The microbiota then has a complex history, with a first period (until approximately age 1) during which it has a rather simple composition (with Bifidobacteria being usually highly abundant in human milk-fed infants) but it also changes rapidly, and a second period during which the microbiota becomes highly diverse (more than 1,000 species, with a clear domination of Firmicutes and Bacteroidetes), indeed unique to each individual, and stabilizes (Candela, Biagi, Maccaferri, Turroni, \& Brigidi, 2012). It is even clearer in the many cases of parasitic symbioses where the association is transient, for example because the parasite leaves the first host to colonize a second host, or because the host eliminates the parasite via its immune system. Importantly, even a very transient interaction between two living things can lead to very significant changes in their respective internal organizations, so there is no direct link between the robustness and durability of a symbiotic interaction and the extent to which it impacts the internal organization of the partners. In conclusion, the double phenomena of merging and splitting happen successively in many instances of symbiotic interactions, probably reflecting complex physiological, ecological, and evolutionary interactions between the two partners.

From all the examples examined here, it can be concluded that symbiotic events of merging and splitting are extremely frequent in nature, which makes Hull's analyses and diagrams even more useful that they might have seemed when the paper was published in 1978. The ubiquity of symbiosis decisively strengthens Hull's point that genidentity is the best way to capture the individuality of biological entities through time. Indeed, it seems clear that using an essentialist account based on genetic homogeneity or an account based on similarity would be entirely inadequate. Only the idea of a continuous change enables us to follow in detail what contributes to the construction of a given living thing, and, here again, the criterion of the degree of disruption of internal organization seems a suitable guide to understand biological diachronic individuality.

\section{How the genidentity view helps define what an organism is}

The genidentity view seems very useful to understand biological identity. Nevertheless, it faces a series of important challenges, and in fact it is likely that any process-based view of the living world will also have to meet those challenges. The basic idea at the heart of the genidentity view is to follow a biological process through time. But how to choose adequately which processes to follow? And how to follow them in practice?

In my view, those questions are very important, and the answer to them will depend on who asks them, and for what purpose. This is where it becomes clear that one of the main interests of the genidentity view is that it places the emphasis on an epistemological, rather than ontological, approach to processes. I do not think that it is possible to prove the ontological claim that the biological world is "really" made of processes, and, if this is indeed 
the claim process philosophers of biology want to make, then they must give an argument for it. However, it is possible to give good arguments in favor of the adoption of an epistemological process view, and to show that, from this epistemological point of view, the decision to interpret the living world in terms of processes (rather than already individualized things) makes an important difference to the scientific work, because it leads to different perspectives and potentially to different experimental programs.

Biologists will decide which process or processes to follow according to their working questions. For example, one may ask how reproduction is achieved in a given species, or how metabolism is maintained in a cell, or how DNA transcription into RNA occurs. These different processes happen at different levels, and involve many different entities. What is crucial is to decide which process will be followed, and which criteria can help us consider that we are dealing with one continuous process. This is exactly the question raised by Hull, but he did so at a very general level, by talking about the maintaining or disruption of the "internal organization" of an organism or a species. In my view, Hull was definitely on the right track, but the notion of internal organization needs to be defined much more precisely in each specific biological context.

Here I suggest to define in precise terms what internal organization and its maintaining/disruption mean at the level of an organism (a similar reflection can be produced, and is indeed produced, about the species level; see, e.g., (Haber, 2016)). More precisely, I suggest that immunity helps offer a more precise conception of genidentity applied to organisms (see also (Pradeu, 2012: 248-249)). In all species (animals, plants, and also prokaryotes), the immune system plays a decisive role in the delineation of the boundaries of the organism, because it constitutes a principle of inclusion/exclusion: the immune system is responsible for the rejection or tolerance of any given entity, which means that the immune system determines which entities will be part of the organism, and which won't. Importantly, this discrimination mechanism is not based on the traditional "self" vs. "nonself" distinction, according to which an organism would immunologically reject all foreign entities and would immunologically accept only constituents originating from the organism itself. Actually, every organism harbors huge quantities of genetically foreign entities, and triggers everyday effector immune responses that target endogenous constituents. ${ }^{2}$

More precisely, an immunological approach leads to a definition of the organism based on the distinction between two different levels, that of biochemical interactions, and that of immune interactions, both necessary to delineate the organism. From that point of view, an organism can be defined as follows:

Def. Organism = a functionally integrated whole, made up of heterogeneous constituents that are locally interconnected by strong biochemical interactions, and controlled by systemic immune interactions. (Pradeu, 2010); (Pradeu, 2012)).

This definition means that when entities interact through regular biochemical interactions and are actively tolerated by the continuous action of an immune system, then they are part of a higher-level entity that should be called an "organism." Of course, this definition puts a strong emphasis on the role of the immune system in the definition of the organism, but it does so

\footnotetext{
${ }^{2}$ Much more specifically, the discontinuity theory of immunity that I have constructed with immunologists ((Pradeu \& Carosella, 2006a); (Pradeu, Jaeger, \& Vivier, 2013)) reflects directly a genidentity perspective. Indeed, a crucial claim of the most elaborate versions of the genidentity view, including Reichenbach's (see Guay \& Pradeu, 2016b), is that what matters to understand diachronic identity is not the degree of change (does it change a lot?), but the rate of change (does it change rapidly?) Now, the discontinuity theory of immunity is exactly based on the principle that the immune system responds to sudden modifications of the antigenic motifs with which it interacts (for further details, see (Pradeu, 2012)).
} 
based on the argument that the immune system plays a decisive role in the delineation of the boundaries of any organism. This definition rests on the recognition of two layers of interactions (biochemical interactions and immune interactions), which can be seen as a way to make more precise process approaches to the living world. What is suggested here is that there can exist some coalescences of interrelated processes, such as the organism, and that following such a coalescence of processes through time might rest on the identification of higher-level processes that control lower-level processes. Here, indeed, I suggest that an organism is a local concentration of intertwined biochemical processes, under the control of higher-level immunological processes. More generally, it is certainly crucial for a process philosophy to identify not only processes in general, but also "bundles" of processes (here, the organism), and to ask what makes the unity and cohesiveness of these "bundles" through time.

The crucial point is that, with the above definition of the organism, we do not start with a preexisting delineation of the organism and subsequently say that the immune system controls this preexisting delineation. Quite the contrary, we start with biochemical and immunological interactions and, from the observation of how these interactions work, we deduce what the boundaries of the organism are. In this view, therefore, what comes first is interactions, and the organism "supervenes" on those interactions. To understand this point fully, it is useful to move away from familiar mammalian examples, and to examine more complex cases of biological individuality, in particular colonial organisms. A particularly illuminating case is that of Botryllus schlosseri (see Figure 4). Botryllus, born as a chordate tadpole larva, then metamorphs into a sessile, invertebrate juvenile, after which the juvenile begins a lifelong, recurring budding process, resulting in a colony of expanding, asexually derived individuals. The colony is made of genetically identical individuals ("zooids") united by a common extracorporeal vasculature. The zooids and vasculature are embedded in a cellulose-based tunic, and the extracorporeal vasculature ramifies throughout this matrix and at the periphery terminates in finger-shaped projections called "ampullae." When two colonies meet, an allorecognition reaction occurs, which leads either to vascular fusion or to rejection. Allorecognition is controlled by a single, highly polymorphic locus (the $\mathrm{Fu} / \mathrm{HC}$ ), and the rejection is realized through the triggering of an immune response ((Scofield, Schlumpberger, West, \& Weissman, 1982); (Nyholm et al., 2006); (McKitrick \& De Tomaso, 2010); (McKitrick, Muscat, Pierce, Bhattacharya, \& De Tomaso, 2011)).

In the case of Botryllus schlosseri, as in many other cases of colonial organisms, it is very difficult to say whether what should be counted as an individual organism is each zooid, or the colony as a whole, or perhaps both. In fact, common sense cannot decide between those options. Now, according to the view presented here, it is the observation of how immune responses occur that tells us what should be counted as an individual organism. As illustrated by Figure 4, immunologically controlled fusion or rejection in Botryllus schlosseri occurs at the level of the whole colony, so this is the colony that must be counted as an individual organism according to the definition presented above.

[Insert Figure 4 about here] 


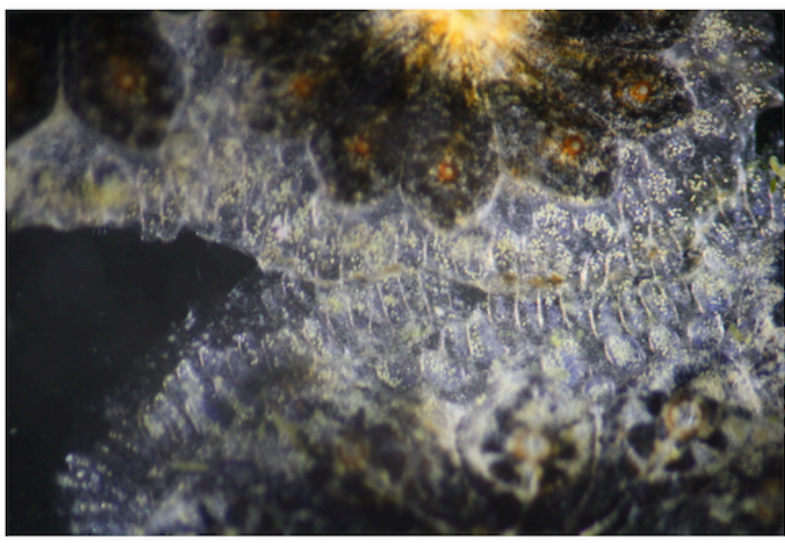

(A)

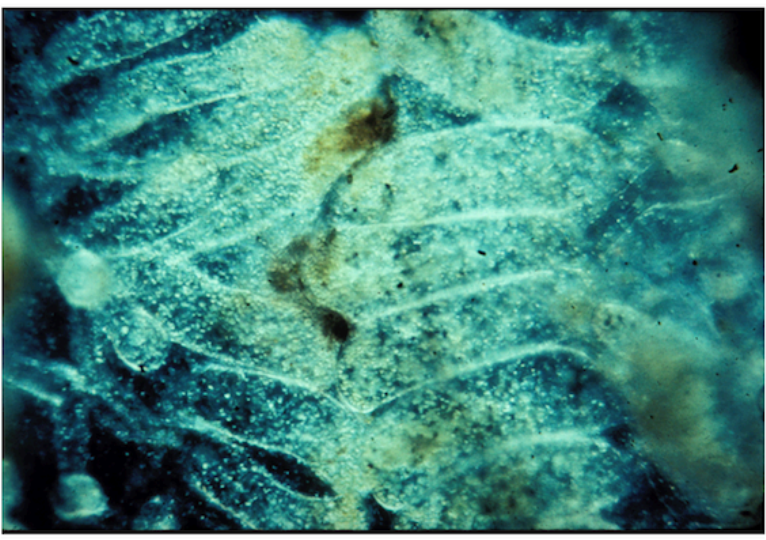

(B)

Figure 4. Rejection between two colonies of Botryllus schlosseri.

Panel A shows an example of rejection between two colonies of Botryllus schlosseri at the level of the colonies themselves; the brown zones at the point of contact between the ampullae (the finger-like structures at the center of the image) show the starting point of the reaction of rejection. Panel B shows an example of rejection between two colonies of Botryllus schlosseri at the much more precise level of the ampullae. (Photographs courtesy of Tony De Tomaso, University of California, Santa Barbara).

The example of Botryllus illustrates one very important advantage of the approach presented here: we start with an indistinct, un-individualized reality, about which common sense and perception have little to say, and it is the decision to follow immunological processes that leads us to conclude, in a scientifically precise way, about what counts as an individual entity, and what its boundaries are.

\section{Genidentity as a way to shed light on the notion of biological process: "Priority" as the central question}

I believe that the multi-layered genidentity approach developed here can be useful to the current trend towards a process biology ((Dupré, 2012); (Bapteste \& Dupré, 2013); (Dupré, 2014)).

First, it emphasizes the importance of an epistemological approach to processes. Though process proponents often think in ontological terms (it is very explicit, e.g., in (Bapteste \& Dupré, 2013)), I do not think that they have hitherto offered compelling arguments for this view. With an epistemological approach, the aim is, more modestly, to show that a process view can make a difference to the actual work of biologists, as a question framed in terms of which processes biologists are interested in, and how they should follow those processes through time. (A nice example is offered by (Dupré \& Guttinger, 2016)).

Second, it clarifies the idea, often expressed by process philosophers, that we live in a world of change. According to the genidentity view, what is interesting is to study how things change, at which pace, and when they start and cease to exist. Within such a perspective, change is pervasive, and what is derivative is not change, but the apparent absence of change, i.e., regularities and sameness, and therefore even apparent stability must be explained in terms of constantly changing processes.

Third, and perhaps most importantly, the genidentity view shows that the crucial claim of a process approach is in fact a claim about priority. Indeed, a process approach does not so much emphasize the importance of change as such (substantialist philosophers perfectly admit that every substance changes constantly) as it asks which comes first between the "thing" and 
the "process," to which it answers that things come after processes, and derive from them. In other words, the important move of a processual perspective is not, in my view, to go from individuals to processes (by saying, for instance, that individuals are in fact processes), but from processes to individuals (as scientists or philosophers, we decide to follow some scientifically meaningful processes, and individuals supervene on these processes). This is exactly what I have tried to illustrate with the case of immunology: in that case, it is scientifically identified processes that tell us where the individual lies, and what its boundaries are, and not vice versa. We cannot start with the "thing" Botryllus schlosseri, because precisely we just don't know where a Bottrylus schlosseri starts and ends; the only solution is to start with processes, namely, I suggested, biochemical and immune processes, and it is the realization of those processes that tells us where the individual is and what its boundaries are. The example of Botryllus schlosseri constitutes in fact a good model for thinking more generally about the individuation of living entities in other species: we cannot assume that we start by identifying an entity, and then ask which processes occur in that entity, because we cannot trust our intuitions and perceptions to identify living entities, so in each case (even in seemingly "intuitive" cases, such as humans) it is necessary to start with scientifically well-defined processes (here, immunological processes), and it is those processes that tell us where the individual is and what its boundaries are.

\section{Conclusion}

The genidentity view seems particularly well suited to understand the diachronic identity of living things. Given the frequency of events such as extensive structural changes (e.g., through metamorphosis), splitting, and fusion, conceptions of biological identity based on similarity or substance are highly problematic. Hull (1978) had perceived this point very well, but we have seen that recent work on symbiosis shows that his view is probably even more compelling today than it was in the 1970s. So the first lesson of the present chapter is that the genidentity view is a very satisfying way to conceive of biological identity.

The second lesson of this chapter is that the genidentity view sheds an important light on process views in biology and philosophy of biology ((Dupré, 2012); (Bapteste \& Dupré, 2013); (Dupré, 2014)). Indeed, it emphasizes the importance of an epistemological and multilayered approach to processes, and it suggests that the main claim of a process view is one of priority, namely that processes come first and make it possible to define things, and not the other way around.

Even though the notion of genidentity has not been very popular among philosophers of science, there is still perhaps much we can learn from it.

\section{Acknowledgments}

I would like to thank Alexandre Guay for our long-lasting mutualistic collaboration. For previous discussions on identity, genidentity, and processes, I thank Giovanni Boniolo, John Dupré, Adam Ferner, Steven French, Peter Godfrey-Smith, Matt Haber, Johanna Seibt, David Wiggins, and Charles Wolfe. Three anonymous referees made very useful comments on the first draft of this chapter. This project has received funding from the European Research Council (ERC) under the European Union's Horizon 2020 research and innovation programme - grant agreement $n^{\circ} 637647$ - IDEM. 


\section{References}

Bapteste, E., \& Dupré, J. (2013). Towards a processual microbial ontology. Biology \& Philosophy, 28(2), 379-404. http://doi.org/10.1007/s10539-012-9350-2

Bapteste, E., Lopez, P., Bouchard, F., Baquero, F., McInerney, J. O., \& Burian, R. M. (2012). Evolutionary analyses of non-genealogical bonds produced by introgressive descent.

Proceedings of the National Academy of Sciences, 109(45), 18266-18272. http://doi.org/10.1073/pnas.1206541109

Baumann, P., Baumann, L., Lai, C. Y., Rouhbakhsh, D., Moran, N. A., \& Clark, M. A. (1995). Genetics, physiology, and evolutionary relationships of the genus Buchnera: intracellular symbionts of aphids. Annual Review of Microbiology, 49, 55-94. http://doi.org/10.1146/annurev.mi.49.100195.000415

Bézier, A., Annaheim, M., Herbinière, J., Wetterwald, C., Gyapay, G., Bernard-Samain, S., ... Drezen, J.-M. (2009). Polydnaviruses of braconid wasps derive from an ancestral nudivirus. Science (New York, N.Y.), 323(5916), 926-930.

http://doi.org/10.1126/science. 1166788

Boniolo, G., \& Carrara, M. (2004). On Biological Identity. Biology and Philosophy, 19(3), 443-457. http://doi.org/10.1023/B:BIPH.0000036163.02581.15

Bosch, T. C. G., \& McFall-Ngai, M. J. (2011). Metaorganisms as the new frontier. Zoology (Jena, Germany), 114(4), 185-190. http://doi.org/10.1016/j.zool.2011.04.001

Bouchard, F. (2010). Symbiosis, lateral function transfer and the (many) saplings of life. Biology \& Philosophy, 25(4), 623-641. http://doi.org/10.1007/s10539-010-9209-3

Bouchard, F., \& Huneman, P. (2013). From Groups to Individuals: Perspectives on Biological Associations and Emerging Individuality. Cambridge, MA: MIT Press.

Candela, M., Biagi, E., Maccaferri, S., Turroni, S., \& Brigidi, P. (2012). Intestinal microbiota is a plastic factor responding to environmental changes. Trends in Microbiology, 20(8), 385391. http://doi.org/10.1016/j.tim.2012.05.003

Doolittle, W. F., \& Bapteste, E. (2007). Pattern pluralism and the Tree of Life hypothesis. Proceedings of the National Academy of Sciences, 104(7), 2043-2049.

http://doi.org/10.1073/pnas.0610699104

Dupré, J. (2012). Processes of Life: Essays in the Philosophy of Biology. Oxford \& New York: Oxford University Press. Retrieved from http://www.oxfordscholarship.com/view/10.1093/acprof:oso/9780199691982.001.0001/acpro f-9780199691982

Dupré, J. (2014). Animalism and the Persistence of Human Organisms. The Southern Journal of Philosophy, 52, 6-23. http://doi.org/10.1111/sjp.12065

Dupré, J., \& Guttinger, S. (2016). Viruses as living processes. Studies in History and

Philosophy of Biological and Biomedical Sciences. http://doi.org/10.1016/j.shpsc.2016.02.010 Dupré, J., \& O’Malley, M. (2009). Varieties of Living Things: Life at the Intersection of Lineage and Metabolism. Philosophy \& Theory in Biology, 1. http://doi.org/http://dx.doi.org/10.3998/ptb.6959004.0001.003

Edson, K. M., Vinson, S. B., Stoltz, D. B., \& Summers, M. D. (1981). Virus in a parasitoid wasp: suppression of the cellular immune response in the parasitoid's host. Science (New York, N.Y.), 211(4482), 582-583.

Espagne, E., Dupuy, C., Huguet, E., Cattolico, L., Provost, B., Martins, N., ... Drezen, J. M. (2004). Genome sequence of a polydnavirus: insights into symbiotic virus evolution. Science (New York, N.Y.), 306(5694), 286-289. http://doi.org/10.1126/science.1103066 Gilbert, S. F., \& Epel, D. (2015). Ecological Developmental Biology (2nd edition). Sunderland, Massachusetts, U.S.A: Sinauer Associates, Inc. Guay, A., \& Pradeu, T. (2016a). Individuals Across the Sciences. New York: Oxford 
University Press.

Guay, A., \& Pradeu, T. (2016b). To Be Continued: The Genidentity of Physical and Biological Processes. In A. Guay \& T. Pradeu (Eds.), Individuals Across the Sciences (pp. 317-347). New York: Oxford University Press.

Haber, M. H. (2016). The Biological and the Mereological. In A. Guay \& T. Pradeu (Eds.), Individuals Across the Sciences (pp. 295-316). Oxford University Press. Retrieved from http://www.oxfordscholarship.com/view/10.1093/acprof:oso/9780199382514.001.0001/acpro f-9780199382514-chapter-16

Hawley, K. (2004). How Things Persist. Oxford University Press.

Hull, D. (1992). Individual. In E. F. Keller \& E. A. Lloyd (Eds.), Keywords in Evolutionary Biology (pp. 181-187). Cambridge, MA: Harvard University Press.

Hull, D. L. (1978). A Matter of Individuality. Philosophy of Science, 45(3), 335-360.

Hull, D. L. (1986). Conceptual Evolution and the Eye of the Octopus. In G. J. W. D. and P. W. Ruth Barcan Marcus (Ed.), Studies in Logic and the Foundations of Mathematics (Vol. 114, pp. 643-665). Elsevier. Retrieved from

http://www.sciencedirect.com/science/article/pii/S0049237X09707177

Hull, D. L. (2001). Science and selection: essays on biological evolution and the philosophy of science. Cambridge, U.K. ; New York: Cambridge University Press.

Kripke, S. A. (1980). Naming and necessity (Rev. and enl. ed). Oxford: Blackwell.

Leibniz, G. W. (1916). New essays concerning human understanding. (K. Gerhardt, Ed., A. G. Langley, Trans.) ( $<2 \mathrm{~d}$ ed. $>$ ). Chicago [etc.]: The Open Court Publishing Company.

Lewin, K. (1922). Der Begriff der Genese in Physik, Biologie und Entwicklungsgeschichte: eine Untersuchung zur vergleichenden Wissenschaftslehre. Berlin: Springer.

Locke, J. (1975). An essay concerning human understanding. (P. H. Nidditch, Ed.). Oxford : New York: Clarendon Press ; Oxford University Press.

Margulis, L., \& Fester, R. (Eds.). (1991). Symbiosis as a source of evolutionary innovation: speciation and morphogenesis. Cambridge, Mass: MIT Press.

Margulis, L., \& Sagan, D. (2002). Acquiring Genomes: A Theory of the Origins of Species. Basic Books.

McFall-Ngai, M., Hadfield, M. G., Bosch, T. C. G., Carey, H. V., Domazet-Lošo, T., Douglas, A. E., ... Wernegreen, J. J. (2013). Animals in a bacterial world, a new imperative for the life sciences. Proceedings of the National Academy of Sciences of the United States of America, 110(9), 3229-3236. http://doi.org/10.1073/pnas.1218525110

McFall-Ngai, M. J. (2002). Unseen Forces: The Influence of Bacteria on Animal

Development. Developmental Biology, 242(1), 1-14. http://doi.org/10.1006/dbio.2001.0522

McKitrick, T. R., \& De Tomaso, A. W. (2010). Molecular mechanisms of allorecognition in a basal chordate. Seminars in Immunology, 22(1), 34-38.

http://doi.org/10.1016/j.smim.2009.12.001

McKitrick, T. R., Muscat, C. C., Pierce, J. D., Bhattacharya, D., \& De Tomaso, A. W. (2011). Allorecognition in a Basal Chordate Consists of Independent Activating and Inhibitory

Pathways. Immunity, 34(4), 616-626. http://doi.org/10.1016/j.immuni.2011.01.019

Nyholm, S. V., \& McFall-Ngai, M. J. (2004). The winnowing: establishing the squid-vibrio symbiosis. Nature Reviews. Microbiology, 2(8), 632-642. http://doi.org/10.1038/nrmicro957 Nyholm, S. V., \& McFall-Ngai, M. J. (2014). Animal development in a microbial world. In A. Minelli \& T. Pradeu (Eds.), Towards a Theory of Development (pp. 260-274). Oxford University Press. Retrieved from http://www.oxfordscholarship.com/view/10.1093/acprof:oso/9780199671427.001.0001/acpro f-9780199671427-chapter-17

Nyholm, S. V., Passegue, E., Ludington, W. B., Voskoboynik, A., Mitchel, K., Weissman, I. L., \& De Tomaso, A. W. (2006). fester, a Candidate Allorecognition Receptor from a 
Primitive Chordate. Immunity, 25(1), 163-173. http://doi.org/10.1016/j.immuni.2006.04.011 Oldroyd, G. E. D. (2013). Speak, friend, and enter: signalling systems that promote beneficial symbiotic associations in plants. Nature Reviews. Microbiology, 11(4), 252-263.

http://doi.org/10.1038/nrmicro2990

Padovani, F. (2013). Genidentity and Topology of Time: Kurt Lewin and Hans Reichenbach.

In N. Milkov \& V. Peckhaus (Eds.), The Berlin Group and the Philosophy of Logical

Empiricism (pp. 97-122). Springer Netherlands. Retrieved from

http://link.springer.com/chapter/10.1007/978-94-007-5485-0_5

Pradeu, T. (2010). What is an organism? An immunological answer. History and Philosophy of the Life Sciences, 32, 247-268.

Pradeu, T. (2011). A Mixed Self: The Role of Symbiosis in Development. Biological Theory, 6(1), 80-88. http://doi.org/10.1007/s13752-011-0011-5

Pradeu, T. (2012). The Limits of the Self: Immunology and Biological Identity. New York:

Oxford University Press.

Pradeu, T. (2016). Mutualistic viruses and the heteronomy of life. Studies in History and

Philosophy of Biological and Biomedical Sciences. http://doi.org/10.1016/j.shpsc.2016.02.007

Pradeu, T., \& Carosella, E. (2006a). On the definition of a criterion of immunogenicity.

Proceedings of the National Academy of Sciences USA, 103(47), 17858-17861.

Pradeu, T., \& Carosella, E. (2006b). The self model and the conception of biological identity in immunology. Biology and Philosophy, 21(2), 235-252.

Pradeu, T., Jaeger, S., \& Vivier, E. (2013). The speed of change: towards a discontinuity theory of immunity? Nature Reviews Immunology, 13(10), 764-769.

http://doi.org/10.1038/nri3521

Reichenbach, H. (1956). The direction of time. Berkeley: University of California Press.

Roossinck, M. J. (2015). Move over bacteria! Viruses make their mark as mutualistic

microbial symbionts. Journal of Virology, JVI.02974-14. http://doi.org/10.1128/JVI.02974-14

Round, J. L., \& Mazmanian, S. K. (2009). The gut microbiota shapes intestinal immune

responses during health and disease. Nature Reviews Immunology, 9(5), 313-323.

http://doi.org/10.1038/nri2515

Sapp, J. (1994). Evolution by Association : A History of Symbiosis: A History of Symbiosis.

Oxford University Press, USA.

Scofield, V. L., Schlumpberger, J. M., West, L. A., \& Weissman, I. L. (1982). Protochordate allorecognition is controlled by a MHC-like gene system. Nature, 295(5849), 499-502.

http://doi.org/10.1038/295499a0

Seibt, J. (2013). Process Philosophy. In E. N. Zalta (Ed.), The Stanford Encyclopedia of

Philosophy (Fall 2013). Retrieved from

http://plato.stanford.edu/archives/fall2013/entries/process-philosophy/

Shigenobu, S., \& Wilson, A. C. C. (2011). Genomic revelations of a mutualism: the pea aphid and its obligate bacterial symbiont. Cellular and Molecular Life Sciences: CMLS, 68(8), 1297-1309. http://doi.org/10.1007/s00018-011-0645-2

Sider, T. (2001). Four-dimensionalism: an ontology of persistence and time. Oxford:

Clarendon Press ; New York. Retrieved from http://nrs.harvard.edu/urn-

3:hul.ebookbatch.OXSCH batch:osouk019924443X

Van Inwagen, P. (1990). Material beings. Ithaca, N.Y: Cornell University Press.

Virgin, H. W., Wherry, E. J., \& Ahmed, R. (2009). Redefining chronic viral infection. Cell, 138(1), 30-50. http://doi.org/10.1016/j.cell.2009.06.036

Wallin, I. E. (1927). Symbionticism and the origin of species. Baltimore: Williams \& Wilkins company.

Wiggins, D. (2001). Sameness and substance renewed. Cambridge, UK: Cambridge

University Press. 